\title{
PROSPECTS FOR THE DEVELOPMENT OF NETWORK INTERACTION IN THE TRANSPORT AND LOGISTICS COMPLEX OF THE REGION
}

\author{
Matvey S. Oborin \\ Perm Institute (Branch) of Russian Economic University named after G.V. Plekhanov, Perm, Russian Federation; \\ Perm State National Research University, Perm, Russian Federation; \\ Perm State Agro-Technological University named after Academician D.N. Pryanishnikov, Perm, Russian Federation; \\ Sochi State University, Sochi, Russian Federation
}

\begin{abstract}
The article deals with the current issue of development of the transport and logistics system and transport and logical clusters on the territory of the Russian Federation on the basis of network interaction. The subject of the study is the transport and logistics clusters of Russian regions, their importance in the development of the transport and logistics complex and economy of Russian regions. Scientific and theoretical concepts on the research problem and their hierarchy in the transport and logistics complex of the region are considered. The economic essence of the transport and logistics cluster and its structure elements are described, and the economic characteristics of various groups of enterprises depending on the degree of participation in the main business process are presented. A comparative assessment of the state and functioning of transport and logistics clusters on the territory of Russia with the European network of transport and logistics clusters formed during the strengthening of integration of European economies into a single space is carried out and proposals for their development based on network interaction are made. The main research methods are formal logical, system and situational approaches, and statistical analysis. The need to support the formation of transport and logistics clusters through state programs and strategies, forms of public-private partnership in economy, activation of integration ties and integrated development based on basic enterprises is identified. The indicators of functioning of transport and logical clusters on the example of Belgorod region, Primorye Krai, including the level of development of the regional infrastructure, the degree of involvement of the economic power of the region, regions position on major domestic and global transport corridors are analyzed and studied. Based on the results of the work, proposals for the development of network interaction in the transport and logistics complex of the regions were formulated, prospects and directions for improving the economic efficiency of transport enterprises were determined, and the percentage of losses in the industry was reduced. The application of the results is useful in the development of regional socio-economic and transport development programs.

Key words: transport and logistics system, transport and logistics cluster, transport and logistics network, logistics, transport channel, transport services market, network interaction, regional infrastructure, public policy, innovation.
\end{abstract}

Citation. Oborin M.S. Prospects for the Development of Network Interaction in the Transport and Logistics Complex of the Region. Journal of Volgograd State University. Economics, 2020, vol. 22, no. 3, pp. 53-64. (in Russian). DOI: https://doi.org/10.15688/ek.jvolsu.2020.3.5

УДК 332.1

ББК 65.049(2Poc)-81

Дата поступления статьи: 06.07.2020

Дата принятия статьи: 02.09.2020

\section{ПЕРСПЕКТИВЫ РАЗВИТИЯ СЕТЕВОГО ВЗАИМОДЕЙСТВИЯ В ТРАНСПОРТНО-ЛОГИСТИЧЕСКОМ КОМПЛЕКСЕ РЕГИОНА}

\section{Матвей Сергеевич Оборин}

Пермский институт (филиал) Российского экономического университета им. Г.В. Плеханова, г. Пермь, Российская Федерация;

Пермский государственный национальный исследовательский университет, г. Пермь, Российская Федерация;

Пермский государственный аграрно-технологический университет им. акад. Д.Н. Прянишникова, г. Пермь, Российская Федерация;

Сочинский государственный университет, г. Сочи, Российская Федерация 
Аннотация. В статье рассматривается актуальный вопрос развития транспортно-логистической системы и транспортно-логистических кластеров на территории Российской Федерации на основе сетевого взаимодействия. Предметом исследования являются транспортно-логистические кластеры регионов России, их значение в развитии транспортно-логистического комплекса и экономики субъектов РФ. Проанализированы научно-теоретические понятия по проблеме исследования, их иерархия в транспортно-логистическом комплексе региона. Охарактеризована экономическая сущность транспортно-логистического кластера и элементы его структуры, представлена экономическая характеристика различных групп предприятий в зависимости от степени участия в основном бизнес-процессе. Проведена сравнительная оценка состояния и функционирования транспортно-логистических кластеров на территории России с Европейской сетью транспортно-логистических кластеров, образованных в ходе усиления интеграции экономик европейских стран в единое пространство, разработаны предложения по их развитию на основе сетевого взаимодействия. Основные методы исследования - формально-логический, системный и ситуационный подходы, анализ статистики. Выявлена необходимость поддержки процессов формирования транспортно-логистических кластеров с помощью государственных программ и стратегий, форм государственно-частного партнерства в экономике, активизации интеграционных связей и комплексного развития на основе базовых предприятий. Проанализированы и изучены показатели функционирования транспортно-логистических кластеров на примере Белгородской области и Приморского края, включающие в себя уровень развития региональной инфраструктуры, степень вовлечения экономической мощности региона, позицию региона относительно основных отечественных и глобальных транспортных коридоров. По итогам работы сформулированы предложения по развитию сетевого взаимодействия в транспортно-логистическом комплексе регионов, определены перспективы и направления повышения экономической эффективности транспортных предприятий, уменьшение процента потерь в отрасли. Применение полученных результатов целесообразно при разработке региональных программ социально-экономического и транспортного развития.

Ключевые слова: транспортно-логистическая система, транспортно-логистический кластер, транспортно-логистическая сеть, логистика, транспортный канал, рынок транспортных услуг, сетевое взаимодействие, региональная инфраструктура, государственная политика, инновации.

Цитирование. Оборин М. С. Перспективы развития сетевого взаимодействия в транспортно-логистическом комплексе региона // Вестник Волгоградского государственного университета. Экономика. - 2020. T. 22, № 3. - C. 53-64. - DOI: https://doi.org/10.15688/ek.jvolsu.2020.3.5

\section{Введение}

Транспортная система имеет важнейшее значение для социально-экономического развития субъектов страны и сглаживания диспропорций между регионами. Эффективность развития транспорта и логистики определяется степенью включения отдаленных территорий в более крупные экономические системы, обеспечения доступности для потребителей товаров и услуг, повышения привлекательности для платежеспособного спроса. Программы стратегического развития регионов России затрагивают проблему транспортно-логистического обеспечения и развития инфраструктуры, поскольку данный вид деятельности создает основу для формирования экономики удаленных территорий и повышения темпов роста благополучно развивающихся субъектов, малых городов и муниципалитетов. Исследование направлений оптимизации и создания транспортно-логистических систем в регионах России должно ориентироваться на положительный отечественный и зарубежный опыт.

Исследования направлений развития транспортно-логистических комплексов в условиях интегрированной экономической среды можно условно разделить на несколько групп:

1. Цифровизация и технологическое перевооружение отрасли, внедрение инновационных технологий в процессы управления транспортом и логистикой, создание автоматизированных линий обработки и сортировки грузов, автоматизированных рабочих мест и интеллектуальных систем контроля [Bley et al., 2016; De Haes et al., 2009; Luftman et al., 2012; Reeves et al., 2011; Urbach et al., 2017].

2. Внедрение принципиально новых технологий стратегического планирования и сценарного прогнозирования развития предприятий транспорта и логистики, оценки эффектов влияния на региональные социально-экономические системы, в том числе устойчи- 
вый рост взаимосвязанных видов деятельности и преобразование пространства депрессивных территорий [Dibrell et al., 2013; Kießling et al., 2010; Rohrbeck, 2011; Rohrbeck et al., 2015].

3. Интенсификации процессов кластерообразования в транспортных комплексах и системах под влиянием реализации стратегических программ социально-экономического развития субъектов РФ и программно-целевого подхода в сочетании с рыночными механизмами финансирования и распределения прибыли [Bereznoy, 2015; Bishop et al., 2007; Bodwell et al., 2010; Vecchiato, 2015].

Современный этап развития экономики характеризуется активным формированием интеграционных объединений. Формами таких объединений могут быть транспортно-логистические системы и структуры, схожие с ними по своей организации - транспортно-логистические кластеры (далее - ТЛК), сетевые структуры.

Проблема кластерного и сетевого развития является достаточно актуальной и обусловлена положительным опытом развитых стран в различных видах экономической деятельности (табл. 1).

Основные термины, характеризующие транспорт и логистику, конкретизируются на различных территориальных уровнях: транспортно-логистическая сеть включает интеграционные формы в отрасли (сети, кластеры, стратегические альянсы и другие виды кооперации и партнерства).

\section{Научные подходы \\ к сущности и структуре}

\section{транспортно-логистических кластеров}

Под транспортно-логистической сетью (далее - ТЛС) понимается множество предприятий, функционирующих с целью оказания услуг на основе единого бизнес-процесса и координации коллективного поведения, которое может принимать формы кластеров, ассоциаций, союзов, стратегических альянсов.

Транспортно-логистическая система - конкурентная бизнес-среда со множеством автономных бизнес-единиц с едиными целями и задачами, связанными с транспортным обслуживанием, достижением высокой прибыли и качества услуг. Транспортно-логистические кластеры являются географически локализованной группой транспортных предприятий, сосредоточенных на оказании услуг в границах определенных маршрутов, взаимодействующих с предприятиями взаимосвязанных отраслей. Более подробный обзор определений понятия транспортно-логистических кластеров различными авторами представлен в таблице 2.

Транспортно-логистические кластеры - это сложная форма функционирования региональных систем логистики, которая позволяет сократить имеющиеся издержки субъектов и ускорить темпы системных логистических процессов.

Структура транспортно-логистических кластеров включает в себя несколько элементов физической инфраструктуры, взаимодействующие между собой (см. рис. 1).

Таблича 1

Характеристика интегрированных структур в научных работах

\begin{tabular}{|l|l|}
\hline \multicolumn{1}{|c|}{ Авторы } & \multicolumn{1}{|c|}{ Содержание понятия } \\
\hline Р. Хагтинс [Huggins, 2000] & $\begin{array}{l}\text { Под сетевой структурой понимается взаимодействие нескольких экономи- } \\
\text { ческих агентов, длительно объединенных общими целями }\end{array}$ \\
\hline Дж. Вебстер [Webster, 1995] & $\begin{array}{l}\text { Кооперация бизнес-структур на основе координации экономического пове- } \\
\text { дения центром стратегического планирования, обмена компетенциями, объ- } \\
\text { единения финансовых, технологических ресурсов, связанных единой ин- } \\
\text { формационной средой }\end{array}$ \\
\hline $\begin{array}{l}\text { Ю.С. Богачев, А.М. Октябрь- } \\
\text { ский, Д.А. Рубвальтер [Бога- } \\
\text { чев и др., 2009] }\end{array}$ & $\begin{array}{l}\text { Кооперация на основе объединения высокотехнологичного ресурсного по- } \\
\text { тенциала юридических и физических лиц с целью производства инноваци- } \\
\text { онной продукции на различных территориальных уровнях }\end{array}$ \\
\hline $\begin{array}{l}\text { В.А. Баринов, Д.А. Жмуров } \\
\text { [Баринов и др., 2007] }\end{array}$ & $\begin{array}{l}\text { Совокупность устойчивых контрактов или похожих социальных и экономи- } \\
\text { ческих отношений между участниками системы }\end{array}$ \\
\hline М. Кастельс [Кастельс, 1999] & $\begin{array}{l}\text { Объединение в общий бизнес-процесс на основе ресурсного потенциала не- } \\
\text { зависимых экономических систем }\end{array}$ \\
\hline
\end{tabular}

Примечание. Составлено автором. 
Определение понятия ТЛК у отечественных авторов

\begin{tabular}{|l|l|}
\hline \multicolumn{1}{|c|}{ Автор } & \multicolumn{1}{|c|}{ Содержание понятия } \\
\hline $\begin{array}{l}\text { Т.В. Евтодиева [Евтодиева, } \\
2011]\end{array}$ & $\begin{array}{l}\text { Предприятия, географически локализованные, оказывающие полный цикл } \\
\text { транспортно-логических услуг, включая контроль ресурсов на входе и выходе } \\
\text { бизнес-процесса }\end{array}$ \\
\hline М.В. Пятаев [Пятаев, 2010] & $\begin{array}{l}\text { Объединение отдельных логистических звеньев, связанных между собой } \\
\text { регионально, функцинально и экономически, обеспечивающих перевозоч- } \\
\text { ный процесс и качество услуг на основе получения экономических выгод }\end{array}$ \\
\hline $\begin{array}{l}\text { И.Г. Смирнов [Смирнов, } \\
\text { 2013] }\end{array}$ & $\begin{array}{l}\text { Отраслевые кластеры, чьей конечной продукцией являются транспортно- } \\
\text { логистические услуги в грузовом и пассажирском секторе }\end{array}$ \\
\hline $\begin{array}{l}\text { Д.Г. Федотенков, А.А. Падал- } \\
\text { ко [Федотенков и др., 2014] }\end{array}$ & $\begin{array}{l}\text { Кооперация независимых экономически структур с целью получения кон- } \\
\text { курентных преимуществ на рынках различного уровня и контроля рыноч- } \\
\text { ной доли услуг }\end{array}$ \\
\hline $\begin{array}{l}\text { И.Г. Меньшенина [Меныше- } \\
\text { нина, 2013] }\end{array}$ & $\begin{array}{l}\text { Совокупность компаний, реализующих полный цикл транспортно-логисти- } \\
\text { ческих услуг на определенной территории, получающих преимущества от } \\
\text { совместной деятельности }\end{array}$ \\
\hline
\end{tabular}

Примечание. Составлено автором.

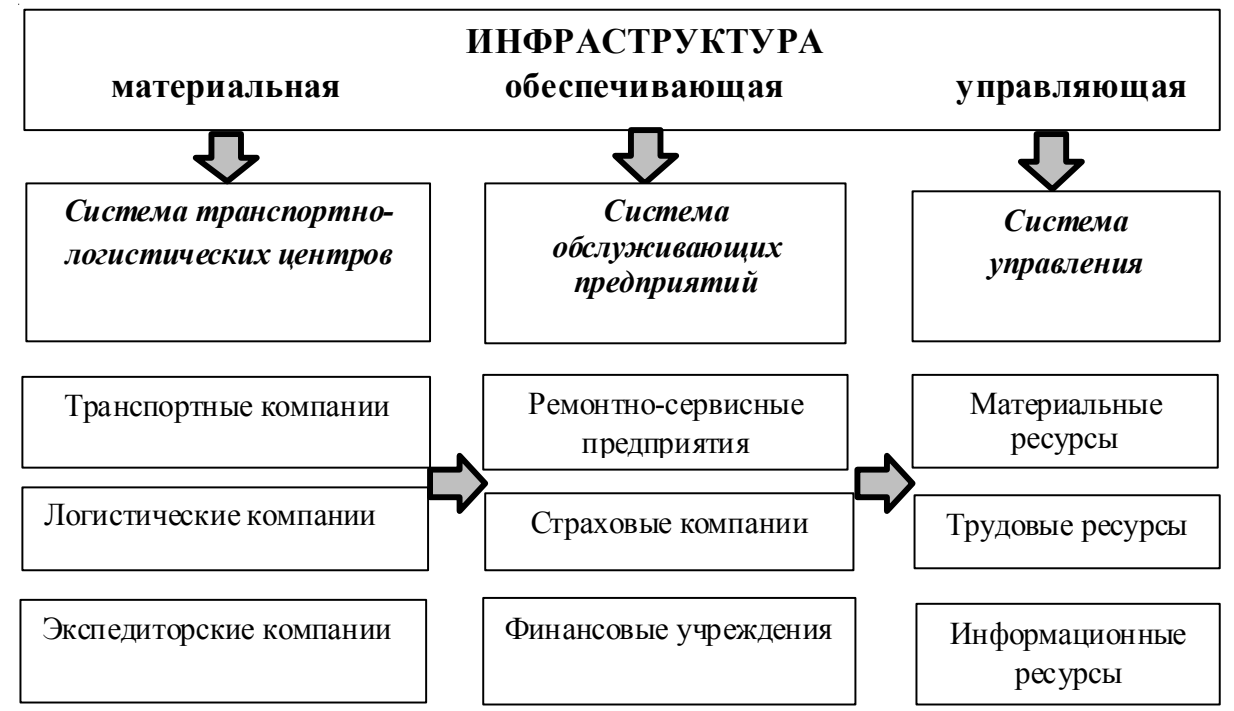

Рис. 1. Структура транспортно-логистического кластера

Примечание. Составлено автором по: [Меньшенина и др., 2008].

Физическая инфраструктура - это автомобильные и железные дороги, водные и воздушные пути сообщения. Ее элементы представляют собой компании, осуществляющие определенный вид работ и услуг, которые, так или иначе, связаны с обработкой транспортных каналов. ТЛК формируются на основе принципов взаимодействия всех своих субъектов:

1) создание единой ресурсной и институциональной среды;

2) реализации системного инновационного процесса на различных этапах бизнеспроцесса;

3) разработки совместно с научными институтами и образовательными организациями;
4) проведение кампаний по повышению квалификации персонала организационных объединений [Прокофьева и др., 2011].

К основным типам транспортно-логистических кластеров относятся такие геополитические, социально-экономические, стратегические и тактические объединения, как:

1) региональные ТЛК: чаще всего формируются в рамках определенного субъекта страны; по своей структуре являются прототипом региональной транспортно-логистической системы, за исключением некоторых аспектов, приведенных выше в отличиях между ТЛК и ТЛС;

2) межрегиональные ТЛК: базируются на территории нескольких государств, в которых 
ядром выступает более экономически развитая страна; связи формируются с учетом особенностей национальных экономик и законодательства, обмена результатами, управленческим опытом и инновационными результатами, способствующими достижению задач, стоящих перед бизнесом в рамках транспортно-логистической политики;

3) обслуживающие глобальные ТЛК: это объединения экономических агентов на соседних территориях с международными транспортными коридорами, способствующие росту темпов и объемов товарно-логистических потоков и повышению качества на каждом этапе процесса обслуживания [Прокофьева и др., 2011].

\section{Модель \\ транспортно-логистического кластера}

Модель транспортно-логистического кластера включает в себя большое количество структурных элементов. Основная модель ТЛК представлена на рисунке 2. Рассмотрим элементы кластерной модели более подробно.
1. Ядро кластера - предприятия, оказывающие базовые услуги или выпуск основной продукции кластера, вокруг которых сосредоточен весь бизнес-процесс с учетом экономической специализации, преимуществ территории. К ним относятся крупные компании и центры, подразделения транснациональных корпораций, транспортно-логистические узлы.

2. Обслуживающие предприятия, деятельность которых может быть не связана с основными услугами, но может оказывать существенное влияние на качество, конечные или промежуточные результаты всего бизнес-процесса: финансово-кредитные учреждения, сервисные, информационно-аналитические компании, склады и центры по переработке и сортировке грузов.

3. Предприятия, осуществляющие вспомогательные функции, связанные с аутсорсинговыми и посредническими операциями, которые оптимизируют деятельность обслуживающих и основных компаний.

4. Инфраструктура и институциональная среда - это научно-исследовательские институты и лаборатории, технопарки, наукограды,

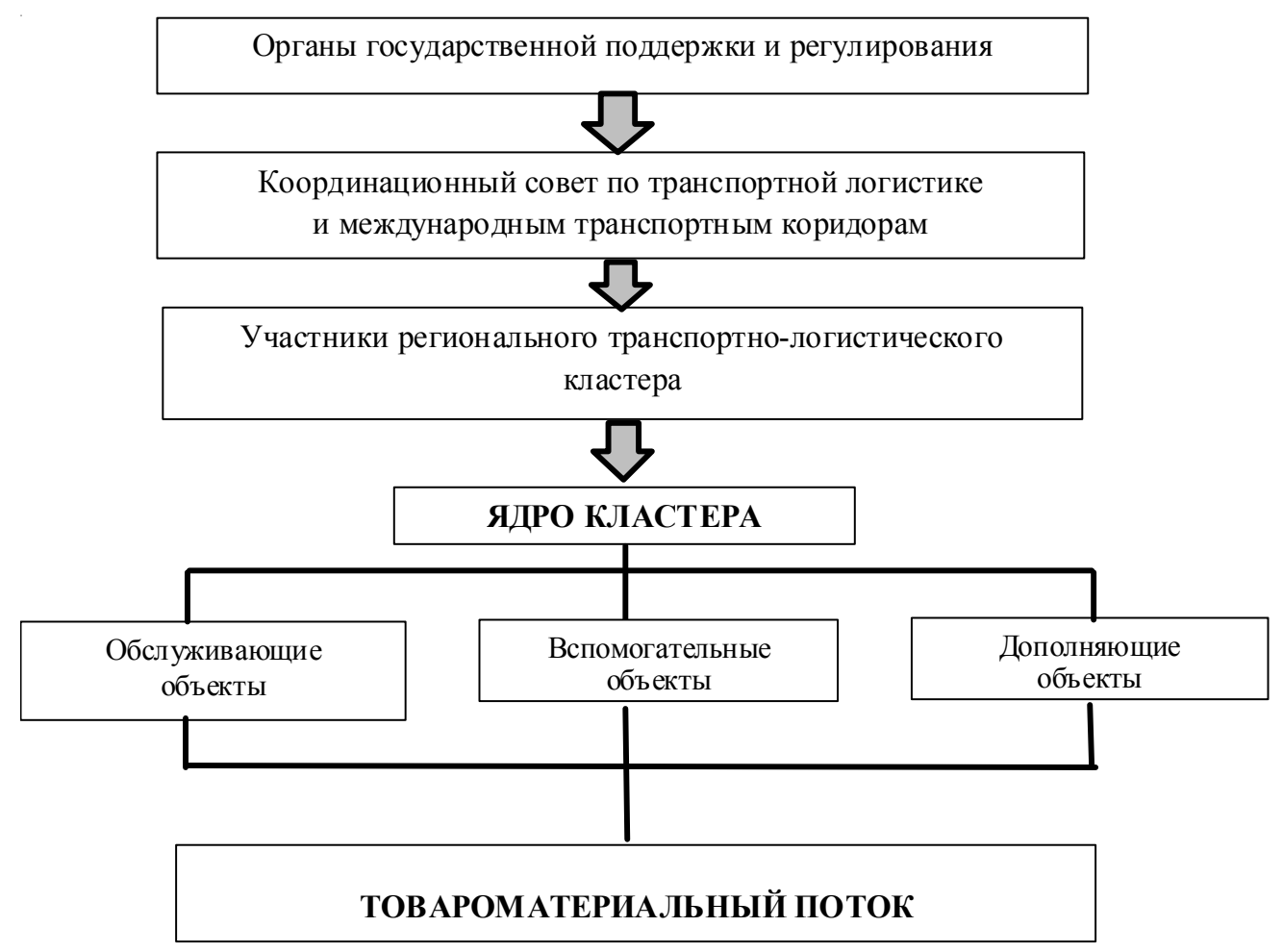

Рис. 2. Модель ТЛК и ее элементы

Примечание. Составлено автором. 
которые напрямую обеспечивают деятельность объектов ядра.

К основным задачам транспортно-логистических кластеров относятся:

1) развитие материально-технологической основы производства товаров и оказания услуг кластеров, образующих единый цикл бизнес-процесса;

2) формирование гибкой ценовой политики на услуги кластера, снижение себестоимости и контроль затрат;

3) повышение эффективности транспортно-логистических коридоров и маршрутов;

4) обеспечение высокой устойчивости к рискам и неопределенности структуры кластера и кооперационных связей между предприятиями;

5) повышение эффективности сетевого взаимодействия и кооперации малого и среднего бизнеса в составе общей логистической системы кластера [Прокофьева и др., 2011].

Исследование транспортно-логистических кластеров связано с эволюцией сетевого взаимодействия как научно-теоретической концепции и заключаются в следующих положениях:

1) транспортно-логистические кластеры - это кластеры услуг, в то время как основными объектами изучения исследователей являлись кластеры товарного производства. Это происходило вследствие главной задачи экономического развития регионов - производства продукции для торговли. Теперь большее внимание уделяется кластерам услуг по мере роста их сегмента;

2) данные образования имеют высокую значимость в формировании социально-экономического пространства регионов и государств.

\section{Анализ опыта регионов в сфере транспортно-логистической интеграции}

В процессе развития интеграции экономик европейских стран в единое пространство была образована Европейская сеть транспортно-логистических кластеров. На данный момент она насчитывает 25 первичных ТЛК и приблизительно 60 вторичных. Четыре основных первичных кластера - это глобальные логистические кластеры, созданные на базе городов (Париж и Лондон) и городских агломераций (РандстадГолланд и ФранкфуртРейн-Майн).

В связи с образованием Европейской сети транспортно-логистических кластеров часть транспортно-логистических услуг, которые оказываются специализированными провайдерами, составила $40 \%$ общего оборота. Половина всего этого оборота приходится на Великобританию, Францию и Германию.

Наибольшая плотность Европейской сети ТЛК отмечается на территории огромного мегалополиса EuropeanCoreRegion - он же «голубой банан». Такое название этот отрезок сети носит из-за его формы и яркого голубого свечения, которое видно из космоса [Транспортно-логистические кластеры ...].

Что касается региональных ТЛК России, то здесь стоит отметить факторы, содействующие их развитию:

1) уровень развития региональной инфраструктуры;

2) степень экономической мощности региона;

3) позиция региона относительно главных отечественных и глобальных транспортных коридоров.

Наиболее перспективные региональные ТЛК в России находятся в Самарской, Белгородской, Калужской областях и в Приморском крае. Они характеризуются развитой инфраструктурой, большой сетью складских помещений и иными характеристиками, представленными в таблице 3.

Для наглядности были рассмотрены показатели Белгородской области и Приморского края. Приморский край обладает наиболее развитой сетью транспортно-логистического кластера: его поддерживает большое количество государственных и частных компаний, осуществляется много проектов по развитию ТЛК, реализуются более глобальные цели, чем у других регионов.

Для более полной картины необходимо рассмотреть и другие экономические показатели транспортно-логистических кластеров двух регионов (см. табл. 4).

Как видно из таблицы 4, показатели Белгородской области говорят о том, что она обладает более развитой транспортно-логистической системой. Следовательно, ТЛК Бел- 
Основные характеристики ТЛК Белгородской области и Приморского края

\begin{tabular}{|l|l|l|}
\hline Показатель & \multicolumn{1}{|c|}{ Белгородская область } & \multicolumn{1}{|c|}{ Приморский край } \\
\hline $\begin{array}{l}\text { Цель } \\
\text { создания }\end{array}$ & $\begin{array}{l}\text { Объединение всех грузопотоков, ми- } \\
\text { нимизация периода обработки товаров, } \\
\text { расширение ассортимента услуг }\end{array}$ & $\begin{array}{l}\text { Внедрение в ТЛС Азиатско-Тихоокеанского регио- } \\
\text { на, соответствие ее стандартам }\end{array}$ \\
\hline $\begin{array}{l}\text { Основные } \\
\text { участники }\end{array}$ & $\begin{array}{l}\text { Белгородское отделение ЮВЖД - фи- } \\
\text { лиал ОАО «РЖД», корпорация «Разви- } \\
\text { тие», международный аэропорт «Бел- } \\
\text { город» }\end{array}$ & $\begin{array}{l}\text { ОАО «РЖД», ООО «Большой порт Зарубино», 3АО } \\
\text { «Алсандр Хаус», ОАО «Восточный порт», ФКУ } \\
\text { «Ространсмодернизация», Министерство РФ по раз- } \\
\text { витию Дальнего Востока }\end{array}$ \\
\hline $\begin{array}{l}\text { Проекты } \\
\text { Зона опережающего развития (мульти- } \\
\text { зона)- международный аэропорт-«хаб» } \\
\text { и объекты сопутствующей сервисной и } \\
\text { логистической инфраструктуры }\end{array}$ & $\begin{array}{l}\text { Международный перегрузочный комплекс «Трои- } \\
\text { ца», 3-я очередь углепогрузочного комплекса порта } \\
\text { Восточный, модернизация интермодального «Тер- } \\
\text { минала Астафьева», развитие транспортного узла } \\
\text { «Восточный - Находка», железнодорожный порт } \\
\text { «Приморский» }\end{array}$ \\
\hline
\end{tabular}

Примечание. Составлено автором по: [Романюк и др., 2015].

Таблица 4

Показатели ТЛК Белгородской области и Приморского края

\begin{tabular}{|l|c|c|c|c|c|c|}
\hline \multicolumn{1}{|c|}{ Показатель } & \multicolumn{2}{|c|}{ Белгородская область } & \multicolumn{3}{|c|}{ Приморский край } \\
\cline { 2 - 8 } & 2014 & 2015 & 2016 & 2014 & 2015 & 2016 \\
\hline $\begin{array}{l}\text { Отправление грузов и пассажиров железнодорожным транс- } \\
\text { портом общего пользования, млн т }\end{array}$ & 54,4 & 53,5 & 51 & 13,9 & 13,6 & 12 \\
\hline $\begin{array}{l}\text { Плотность железнодорожных пугей на конец года, км путей } \\
\text { на 10 000 км2 территории }\end{array}$ & 258 & 258 & 258 & 95 & 95 & 95 \\
\hline $\begin{array}{l}\text { Перевозки грузов автомобильным транспортом организаций } \\
\text { всех видов деятельности, млн т }\end{array}$ & 43,3 & 41 & 39,3 & 23,1 & 22,5 & 17,8 \\
\hline $\begin{array}{l}\text { Грузоборот автомобильного транспорта организаций всех } \\
\text { видов деятельности, млн т/км }\end{array}$ & 3352 & 3428 & 3592 & 1264 & 1097 & 1249 \\
\hline $\begin{array}{l}\text { Плотность автомобильных дорог общего пользования с } \\
\text { твердым покрытием, км путей на 1 000 км территории }\end{array}$ & 675 & 704 & 729 & 89 & 93 & 92 \\
\hline
\end{tabular}

Примечание. Составлено автором по: [Транспорт].

городской области имеет больший потенциал, чем ТЛК Приморского края. Несмотря на то что в Приморском крае реализуется большее количество программ по развитию транспортно-логистического кластера, показатели Белгородской области опережают аналогичные по Приморскому краю по всем направлениям. К примеру, количество отправленных грузов и пассажиров путем железнодорожного сообщения в Белгородской области в 2016 г. составило 51 млн т, что в 4 раза больше, чем аналогичные данные по Приморскому краю. Плотность автомобильных дорог общего пользования с твердым покрытием в Белгородской области за 3 года незначительно выросла и составила 729 км путей на 1000 км² территории; в Приморском крае - 92 км путей на 1000 км² территории. Стоит отметить, что практически все показатели занятости транспортно-логистического кластера области и края за последние 3 года незначительно снизились, что говорит о некотором торможении развития транспортно-логистического кластера и в Белгородской области, и в Приморском крае.

\section{Результаты и выводы}

Улучшить состояние ТЛК рассматриваемых субъектов РФ возможно на основе сетевого взаимодействия, которое будет способствовать активизации межрегиональных связей и усилению бизнес-активности (см. рис. 3).

Основными проблемами функционирования региональных транспортно-логистических кластеров являются:

1) недостаточное количество квалифицированных работников, что вызвано несо- 


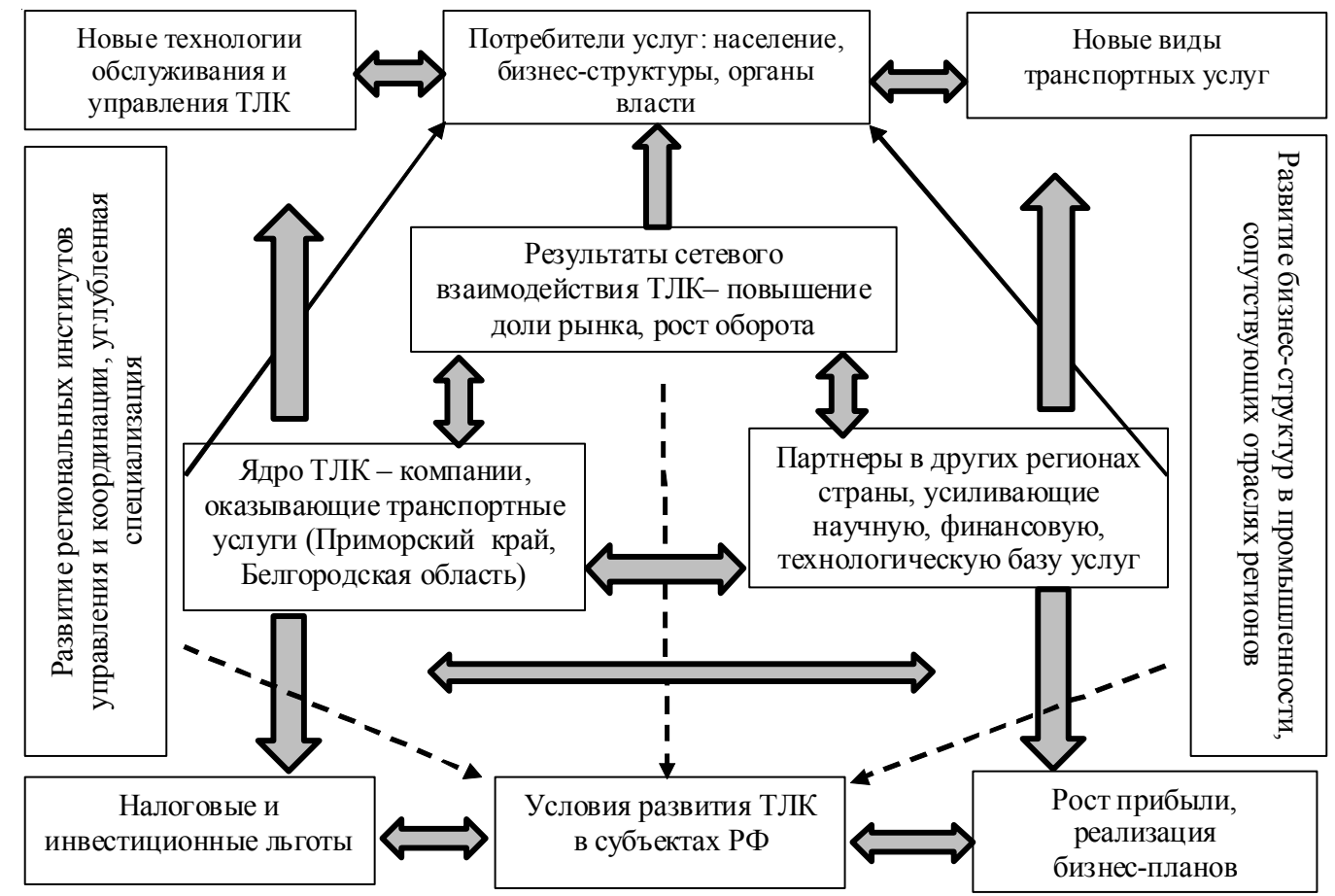

Рис. 3. Перспективы развития сетевого взаимодействия в транспортно-логистическом комплексе региона Примечание. Составлено автором.

ответствием образовательных программ учебных заведений высшего, среднего и профессионального образования современным потребностям и нуждам экономической сферы страны;

2) неспособность предприятия производить инновационные продукты, а также внедрять инновационные технологии в процесс производства, что приводит к достаточно медленным темпам обновления ассортимента выпускаемых предприятиями продуктов и услуг, а также к снижению уровня их потребительских качеств;

3) низкая степень развития организационной структуры кластера, в том числе и в виде недостатка практического стратегического планирования развития кластера, непроработанной структуры системы информационных коммуникаций между всеми субъектами кластера;

4) существующие ограничения к выходу на зарубежный рынок, включающие в себя барьеры, установленные санкциями ведущих экономически развитых стран [Прокофьева и др., 2011].

Таким образом, региональные транспортно-логистические кластеры в некоторых субъектах России уже находятся на достаточно высоком уровне, однако в других регионах требуются внушительные меры для развития ТЛК. Транспортно-логистический кластер это относительно новый феномен, вызванный процессом глобализации мировой экономики, который подразумевает форму деятельности региональных логистических систем, способствующую сокращению имеющихся издержек регионов и увеличению темпов системных логистических процессов.

Транспортно-логистические кластеры способствуют ускоренному экономическому росту регионов страны, положительно влияют на отрасли промышленности, способствуя быстрому перемещению материальных грузов, сокращению временных затрат и издержек. В настоящее время в разных субъектах РФ состояние действующих региональных транспортно-логистические кластеров существенно отличается, что влияет на формирование территориальных стратегий и государственное регулирование отрасли. Наиболее развитыми в транспортном отношении регионами считаются Самарская, Белгородская, Калужская области, Приморский край, что обусловлено наличием большой сети дорог высокого качества, обширных складских помещений. Факторами, влияющими на успешное развитие транспортно-логистических кла- 
стеров, являются уровень развития региональной инфраструктуры, степень экономической мощности региона, географическое положение региона относительно главных отечественных и глобальных транспортных коридоров. Факторами, тормозящими развитие в регионах, выступают дефицит квалифицированных работников, невысокая степень развития организационной структуры кластера, недостаток практического стратегического планирования развития кластера, действующие ограничения к выходу на зарубежный рынок.

В результате проведенного исследования транспортно-логистические кластеры можно охарактеризовать как сложную форму функционирования региональных систем логистики, позволяющую сократить существующие издержки экономических субъектов и ускорить темпы системных логистических процессов. Формирование транспортно-логистических кластеров на региональном пространстве связано с функционированием единой информационно-технологической платформы и оптимизацией ресурсного потенциала транспортных компаний.

Для роста уровня транспортно-логистических кластеров до общепризнанных мировых возможно при эффективном перераспределении всех грузопотоков для рационального развития всех элементов ТЛК, росте качества предоставляемых предприятиями кластера услуг, формировании новых рабочих мест для квалифицированных специалистов в отраслях транспорта и связи, разработке новых стандартов безопасности грузоперевозок и распределения пассажиропотоков, кооперации новых предприятий малого и среднего бизнеca, участвующих в данной сфере деятельности. Транспортно-логистический кластер должен развиваться комплексно, без отрыва от работы своих основных предприятий, а также при помощи поддержки мер государственных стратегий и методов государственно-частного партнерства.

Сетевое взаимодействия является эффективным направлением развития транспортно-логистических комплексов, способствуя росту оборота и прибыли, концентрированию на перспективных видах экономической деятельности, приносящих наибольший доход, адаптируясь к спросу со стороны населения и бизнес-структур. Расширение рыночного присутствия способствует диверсификации рисков базовых компаний (ядра ТЛК) и повышает устойчивость и адаптивность региональных транспортных систем к негативным макроэкономическим факторам.

\section{СПИСОК ЛИТЕРАТУРЫ}

Баринов, В. А. Развитие сетевых формирований в инновационной экономике / В. А. Баринов, Д. А. Жмуров // Менеджмент в России и за рубежом. - 2007. - № 9. - С. 112-122.

Богачев, Ю. С. Механизмы развития инновационной экономики в современных условиях / Ю. С. Богачев, А. М. Октябрьский, Д. А. Рубвальтер // Экономическая наука современной России. 2009. - №2 (45). - С. 65-71.

Евтодиева, Т. В. Логистические кластеры: сущность и виды / Т. В. Евтодиева // Экономические науки. - 2011. - № 4 (77). - С. 78-81.

Кастельс, М. Становление общества сетевых структур / М. Кастельс. - М. : Экос, 1999. - 236 с.

Меньшенина, И. Г. Транспортно-логистический кластер в экономической системе региона / И. Г. Меньшенина // Экономика региона. - 2013. - № 9. - С. 96-112.

Меньшенина, И. Г. Кластерообразование в региональной экономике : монография / И. Г. Меньшенина, Л. М. Капустина. - Екатеринбург : Изд-во Урал. гос. экон. ун-та, 2008. - 154 с.

Прокофьева, Т. А. Методологические аспекты построения кластерной модели транспортно-логистической инфраструктуры региона / Т. А. Прокофьева, В. В. Клименко // Логистика и управление цепями поставок. - 2011. - № 47. C. 31-41.

Пятаев, М. В. Оценка эффективности формирования транспортно-логистических кластеров (на примере Новосибирской области) : дис. ... канд. экон. наук / Пятаев Максим Викторович. - Новосибирск, 2010. - 203 с.

Романюк, Е. В. Транспортно-логистический кластер как инструмент интенсивного рынка логистических услуг России / Е. В. Романюк, Е. Н. Сорока // Логистика- евразийский мост : материалы 10-й Междунар. науч.-практ. конф. Красноярск : Астель, 2015. - С. 253-257.

Смирнов, И. Г. Процессы транспортно-логистической кластеризации в Европейском союзе и Украине: региональный аспект / И. Г. Смирнов // Псковский регионологический журнал. - 2013. - № 15. C. 66-75.

Транспорт // Федеральная служба государственной статистики. - Электрон. текстовые дан. - Ре- 
жим доступа: https://rosstat.gov.ru/folder/ 23455 (дата обращения 05.05.2020). - Загл. с экрана.

Транспортно-логистические кластеры в Европейском Союзе : селектив. обзор. - 2011. - Электрон. текстовые дан.- Режим доступа: http:// cik63.ru/upload/iblock/fb5/fb54e4e23f14 22238e294c7cb7d1e362.pdf (дата обращения: 12.01.2020). - Загл. с экрана.

Федотенков, Д. Г. Транспортно-логистические кластеры как вызов времени в социально-экономическом развитии региона / Д. Г. Федотенков, А. А. Падалко // Проблемы и перспективы экономики и управления : материалы III Междунар. науч. конф. - М. : Эксмо, 2014. C. 59-63.

Bereznoy, A. Changing Competitive Landscape Through Business Model Innovation: The New Imperative for Corporate Market Strategy / A. Bereznoy // Journal of the Knowledge Economy. - 2019. Vol. 10, №4.- - P. 1362-1383.

Bishop, P. The Current State of Scenario Development: An Overview of Techniques / P. Bishop, A. Hines, T. Collins // Foresight. - 2007. - Vol. 9, № 1. - P. 5-25.

Bley, K. Digitization of German Enterprises in the Production Sector - Do they know how 'digitized' they are? / K. Bley, C. Leyh, T. Schäffer// Proceedings of the $22^{\text {nd }}$ Americas Conference on Information Systems (AMCIS 2016), August 11-04, San Diego California, USA. - Atlanta, GA : Association for Information Systems (AIS), 2016. - P. 1-10.

Bodwell, W. Organizational Ambidexterity: Integrating Deliberate and Emergent Strategy with Scenario Planning/W. Bodwell, T. Chermack // Technological Forecasting \& Social Change. - 2010. - Vol. 7, № 1. - P. 193-202.

De Haes, S. An Exploratory Study into IT Governance Implementations and its Impact on Business/IT Alignment / S. de Haes, W. van Grembergen // Information Systems Management. - 2009. Vol. 26, № 2. - P. 123-137.

Dibrell, C. Linking the Formal Strategic Planning Process, Planning Flexibility, and Innovativeness to Firm Performance/C. Dibrell, J. B. Craig, D. O. Neubaum // Journal of Business Research. - 2013. - Vol. 67, № 9. - P. 2000-2007.

Huggins, R. The Success and Failure of Policy-Implanted Inter-Firm Network Initiatives: Motivations, Processes and Structure / R. Huggins // Entrepreneurship and Regional Development. 2000. - Vol. 12. - P. 195-202.

Kießling, M. Overcoming Challenges for Managing IT Innovations in Non-IT Companies / M. Kießling, H. Wilke, L. M. Kolbe // Proceedings of the $16^{\text {th }}$ Americas Conference on Information
Systems (AMCIS 2010), Lima, Peru. - Atlanta, GA : Association for Information Systems (AIS), 2010. - P. 1-9.

Luftman, J. Key Issues for IT Executives 2012: Doing More with Less / J. Luftman, B. Derksen // MIS Quarterly Executive. - 2012. - Vol. 11, № 4. P. 207-218.

Reeves, M. Adaptability: The New Competitive Advantage / M. Reeves, M. Deimler // Harvard Business Review. - 2011. - Vol. 89, № 7/8. P. 134-141.

Rohrbeck, R. Corporate Foresight: Its Three Roles in Enhancing the Innovation Capacity of a Firm / R. Rohrbeck // Technological Forecasting \& Social Change. - 2011. - Vol. 78, № 2. - P. 231-243.

Rohrbeck, R. Corporate Foresight: An Emerging Field with a Rich Tradition / R. Rohrbeck, C. Battistella, E. Huizingh // Technological Forecasting \& Social Change. - 2015. - Vol. 101, № 1. - P. 1-9.

Urbach, N. Digital Business Transformation and the Changing Role of the IT Function / N. Urbach, P. Drews, J. W. Ross // MIS Quarterly Executive. 2017. - Vol. 16, № 2. - P. 1-4.

Vecchiato, R. Strategic Planning and Organizational Flexibilityin Turbulent Environments/ R. Vecchiato // Foresight. - 2015. - Vol. 17, № 3. - P. 257-273.

Webster, J. Networks of Collaboration or Conflict? Electronic data Interchange and Power in the Supply Chain / J. Webster // The Journal of Strategic Information Systems. - 1995. - Vol. 4, № 1. - P. 95-106.

\section{REFERENCES}

Barinov V.A., Zhmurov D.A. Razvitie setevykh formirovaniy v innovactsionnoy ekonomike [The Development of Network Formations in an Innovative Economy]. Menedzhment $v$ Rossii $i$ za rubezhom [Management in Russia and Abroad], 2007, no. 9, pp. 112-122.

Bogachev Yu.S., Oktyabrskij A.M., Rubvalter D.A. Mekhanizmy razvitiya innovatsionnoy ekonomiki v sovremennykh usloviyakh [Mechanisms for the Development of an Innovative Economy in Modern Conditions]. Ekonomicheskaya nauka sovremennoy Rossii [The Economic Science of Modern Russia], 2009, no. 2 (45), pp. 65-71.

Evtodieva T.V. Logisticheskie klastery: sushchnost i vidy [Logistic Clusters: Essence and Types]. Ekonomicheskie nauki [Economic Sciences], 2011, no. 4 (77), pp. 78-81.

Kastels M. Stanovlenie obshchestva setevykh struktur [The Formation of a Society of Network Structures]. Moscow, Ekos Publ., 1999. 236 p. 
Menshenina I.G. Transportno-logisticheskiy klaster v ekonomicheskoy sisteme regiona [Transport and Logistics Cluster in the Economic System of the Region]. Ekonomika regiona [The Economy of the Region], 2013, no. 9, pp. 96-112.

Menshenina I.G., Kapustina L.M. Klasteroobrazovanie v regionalnoy ekonomike: monografiya [Cluster Formation in a Regional Economy. Monograph]. Ekaterinburg, Izd-vo Uralskogo gosudarstvennogo ekonomicheskogo universiteta, 2008. 154 p.

Prokofe'va T.A., Klimenko V.V. Metodologicheskie aspekty postroeniya klasternoy modeli transportno-logisticheskoy infrastruktury regiona [Methodological Aspects of Building a Cluster Model of the Transport and Logistics Infrastructure of the Region]. Logistika $i$ upravlenie tsepyami postavok [Logistics and Supply Chain Management], 2011, no. 47, pp. 31-41.

Pyataev M.V. Otsenka effektivnosti formirovaniya transportno-logisticheskikh klasterov (na primere Novosibirskoy oblasti): dis. kand. ekon. nauk [Evaluation of the Effectiveness of the Formation of Transport and Logistics Clusters (On the Example of Novosibirsk Region). Cand. econ. sci. diss.]. Novosibirsk, 2010. 203 p.

Romanyuk E.V., Soroka E.N. Transportno-logisticheskiy klaster kak instrument intensivnogo rynka logisticheskih uslug Rossii [Transport and Logistics Cluster as a Tool for the Intensive Market of Logistics Services in Russia]. Logistikaevraziyskiy most: materialy 10-y Mezhdunar. nauch.-prakt. konf. [Logistics - Eurasian Bridge: Proceedings of the $10^{\text {th }}$ International Scientific and Practical Conference]. Krasnoyarsk, Astel Publ., 2015,pp. 253-257.

Smirnov I.G. Processy transportno-logisticheskoy klasterizatsii v Evropeyskom Soyuze i Ukraine: regionalnyy aspekt [The Processes of Transport and Logistics Clustering in the European Union and Ukraine: Regional Aspect]. Pskovskiy regionologicheskiy zhurnal, 2013, no. 15, pp. 66-75.

Transport [Transport]. Federalnaya sluzhba gosudarstvennoy statistiki [Federal State Statistics Service]. URL: https://rosstat.gov.ru/ folder/23455 (accessed 5 May 2020).

Transportno-logisticheskie klastery v Evropeyskom Soyuze: selektiv. obzor [Transport and Logistics Clusters in the European Union: Selective Overview], 2011. URL: http://cik63.ru/upload/ iblock/fb5/fb54e4e23f1422238e294c7cb7d1e 362.pdf (accessed 12 January 2020).

Fedotenkov D.G., Padalko A.A. Transportnologisticheskie klastery kak vyzov vremeni $\mathrm{v}$ sotsialno-ekonomicheskom razvitii regiona [Transport and Logistics Clusters as a Time Challenge in the Socio-Economic Development of the Region]. Problemy $i$ perspektivy ekonomiki $i$ upravleniya: materialy III Mezhdunar. nauch. konf. [Problems and Prospects of Economics and Management: Proceedings of the III International Scientific Conference]. Moscow, Eksmo Publ., 2014, pp. 59-63.

Bereznoy, A. Changing Competitive Landscape Through Business Model Innovation: The New Imperative for Corporate Market Strategy. Journal of the Knowledge Economy, 2019, vol. 10, no. 4, pp. 1362-1383.

Bishop P., Hines A., Collins T. The Current State of Scenario Development: An Overview of Techniques. Foresight, 2007, vol. 9, no. 1, pp. 5-25.

Bley K., Leyh C., Schäffer T. Digitization of German Enterprises in the Production Sector - Do They Know How Digitized They Are? Proceedings of the $22^{\text {nd }}$ Americas Conference on Information Systems (AMCIS 2016), August 11-04, San Diego - California, USA. Atlanta, GA, Association for Information Systems (AIS), 2016, pp. 1-10.

Bodwell W., Chermack T. Organizational Ambidexterity: Integrating Deliberate and Emergent Strategy with Scenario Planning. Technological Forecasting \& Social Change, 2010, vol. 7, no. 1, pp. 193-202.

de Haes S., van Grembergen W. An Exploratory Study into IT Governance Implementations and its Impact on Business/IT Alignment. Information Systems Management, 2009, vol. 26, no. 2, pp. 123-137.

Dibrell C., Craig J.B., Neubaum D.O. Linking the Formal Strategic Planning Process, Planning Flexibility, and Innovativeness to Firm Performance. Journal of Business Research, 2013, vol. 67, no. 9, pp. 2000-2007.

Huggins R. The Success and Failure of PolicyImplanted Inter-Firm Network Initiatives: Motivations, Processes and Structure. Entrepreneurship and Regional Development, 2000, vol. 12, pp. 195-202.

Kießling M., Wilke H., Kolbe L.M. Overcoming Challenges for Managing IT Innovations in NonIT Companies. Proceedings of the $16^{\text {th }}$ Americas Conference on Information Systems (AMCIS 2010), Lima, Peru. Atlanta, GA, Association for Information Systems (AIS), 2010, pp. 1-9.

Luftman J., Derksen B. Key Issues for IT Executives 2012: Doing More with Less. MIS Quarterly Executive, 2012, vol. 11, no. 4, pp. 207-218. 
Reeves M., Deimler M. Adaptability: The New Competitive Advantage. Harvard Business Review, 2011, vol. 89, no. 7/8, pp. 134-141.

Rohrbeck R. Corporate Foresight: Its Three Roles in Enhancing the Innovation Capacity of a Firm. Technological Forecasting \& Social Change, 2011, vol. 78, no. 2, pp. 231-243.

Rohrbeck R., Battistella C., Huizingh E. Corporate Foresight: An Emerging Field with a Rich Tradition. Technological Forecasting \& Social Change, 2015, vol. 101, no. 1, pp. 1-9.
Urbach N., Drews P., Ross J.W. Digital Business Transformation and the Changing Role of the IT Function. MIS Quarterly Executive, 2017, vol. 16, no. 2, pp. 1-4.

Vecchiato R. Strategic Planning and Organizational Flexibility in Turbulent Environments. Foresight, 2015, vol. 17, no. 3, pp. 257-273.

Webster J. Networks of Collaboration or Conflict? Electronic data Interchange and Power in the Supply Chain. Journal of Strategic Information Systems, 1995, vol. 4, no. 1, pp. 95-106.

\section{Information About the Author}

Matvey S. Oborin, Doctor of Sciences (Economics), Professor, Department of Economic Analysis and Statistics, Perm Institute (Branch) of Russian Economic University named after G.V. Plekhanov, Gagarina Boulevard, 57, 614070 Perm, Russian Federation; Professor, Department of World and Regional Economy, Economic Theory, Perm State National Research University, Bukireva St, 15, 614990 Perm, Russian Federation; Professor, Department of Management, Perm State Agro-Technological University named after Academician D.N. Pryanishnikov, Petropavlovskaya St, 23, 614990 Perm, Russian Federation; Professor, Department of Management and Technologies in Tourism and Service, Sochi State University, Sovetskaya St, 26a, 354000 Sochi, Russian Federation, recreachin@rambler.ru, https://orcid.org/0000-0002-4281-8615

\section{Информация об авторе}

Матвей Сергеевич Оборин, доктор экономических наук, профессор кафедры экономического анализа и статистики, Пермский институт (филиал) Российского экономического университета им. Г.В. Плеханова, бульвар Гагарина, 57, 614070 г. Пермь, Российская Федерация; профессор кафедры мировой и региональной экономики, экономической теории, Пермский государственный национальный исследовательский университет, ул. Букирева, 15, 614990 г. Пермь, Российская Федерация; профессор кафедры менеджмента, Пермский государственный аграрно-технологический университет им. акад. Д.Н. Прянишникова, ул. Петропавловская, 23, 614990 г. Пермь, Российская Федерация; профессор кафедры управления и технологий в туризме и сервисе, Coчинский государственный университет, ул. Советская, 26a, 354000 г. Сочи, Российская Федерация, recreachin@rambler.ru, https://orcid.org/0000-0002-4281-8615 